\title{
Correction to: A DFT study on the mechanism of the organocatalytic synthesis of a benzoxazine-substituted indolizine derivative
}

\section{Xin Mao ${ }^{1} \cdot$ Sufan Wang ${ }^{1} \cdot$ Yongjia Shang ${ }^{1}$}

Published online: 30 December 2019

(C) Springer-Verlag GmbH Germany, part of Springer Nature 2019

\section{Correction to: J Mol Model (2017) 23: 177}

https://doi.org/10.1007/s00894-017-3328-6

The original version of this article unfortunately contained a mistake. The presentation of Diagram 1, Fig. 2 and Fig. 3 were incorrect. The correct versions are given below.

Diagram 1 Reaction profiles of the $N$-ylide precursor calculated at the B3LYP/6-31 + G(d,p) level of theory, where the blue lines and red lines denote N1-site and N2site reactions, respectively

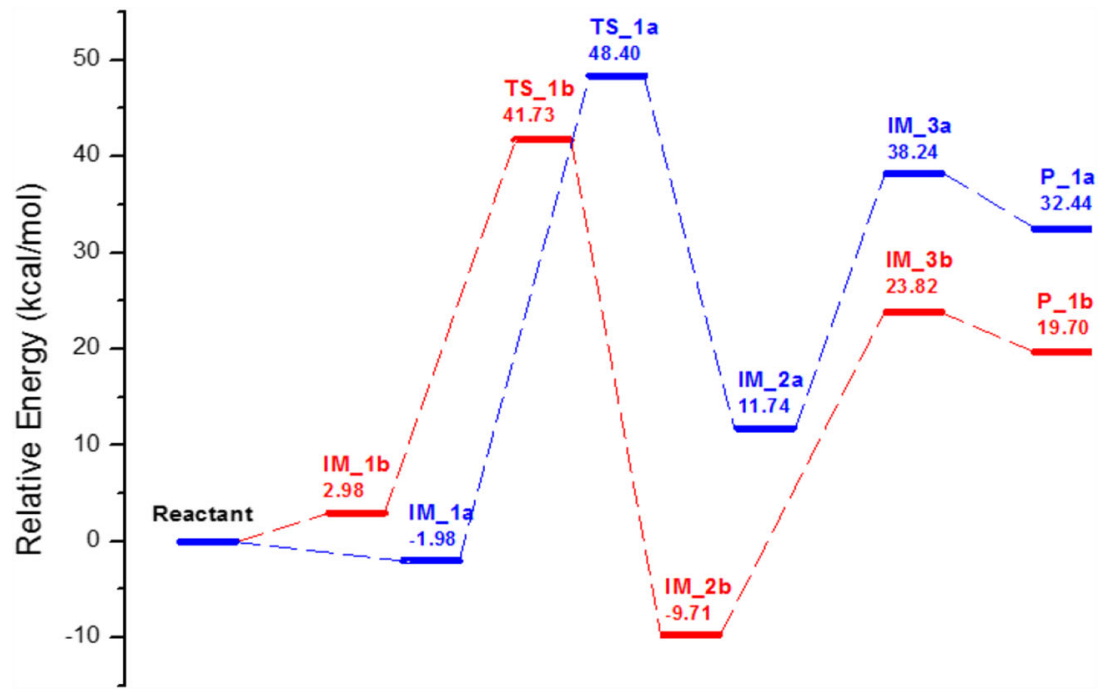

The online version of the original article can be found at https://doi.org/ 10.1007/s00894-017-3328-6

Sufan Wang

sfwang@mail.ahnu.edu.cn

1 College of Chemistry and Materials Science, Anhui Normal

University, Wuhu 241000, People's Republic of China 

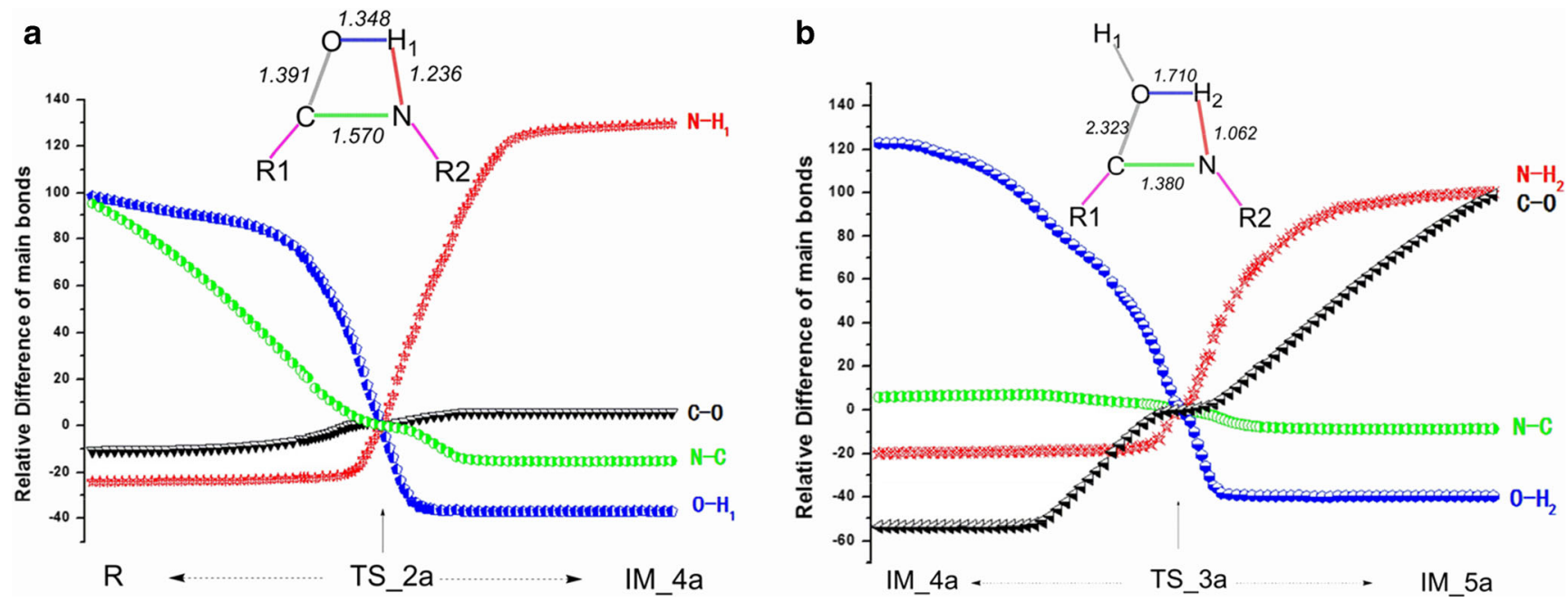

Fig. 2 Characteristic bond length variations during the synthesis of the precursor P_2a
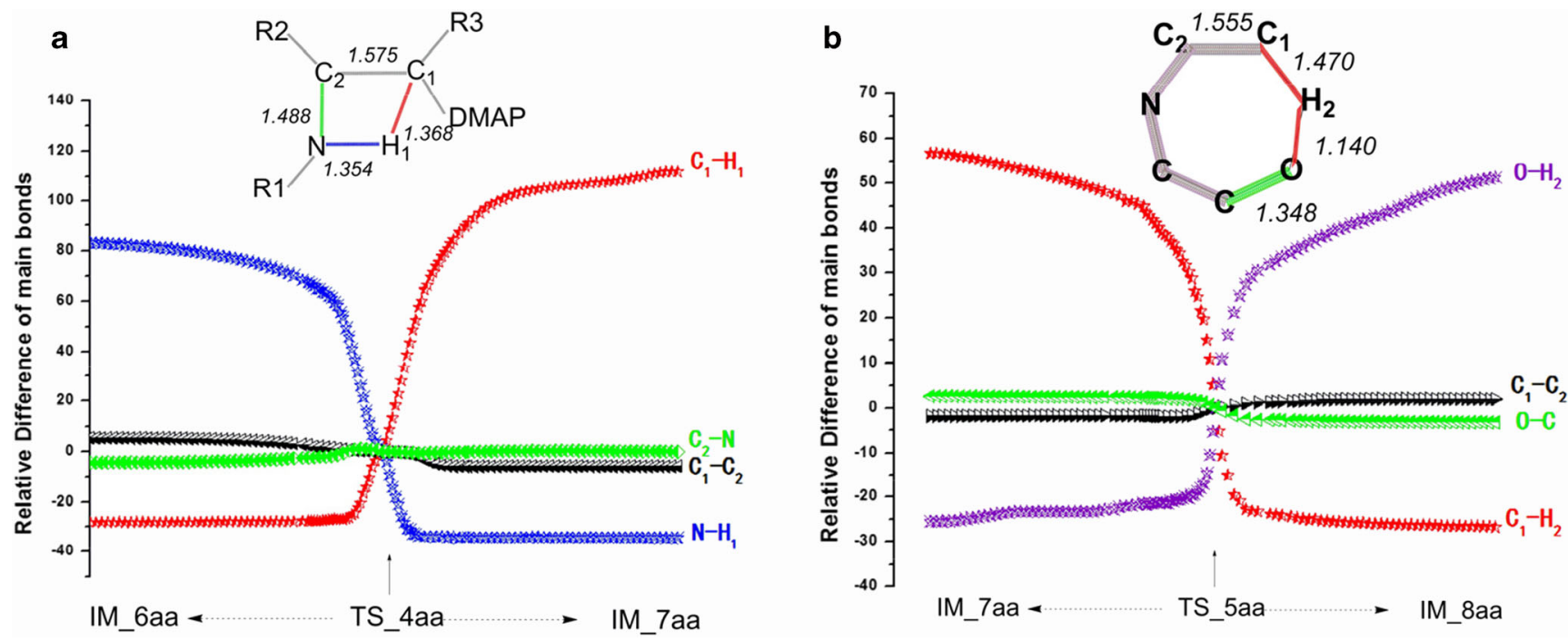

Fig. 3a-b Variations in the lengths of the most relevant bonds in the synthesis of the target product, where a shows the bond distances in the first fourmembered ring and $\mathbf{b}$ presents the bond distances in the seven-membered ring

Publisher's note Springer Nature remains neutral with regard to jurisdictional claims in published maps and institutional affiliations. 